\title{
THE ANTIFIBROTIC POTENTIAL OF RESVERATROL IN SCHISTOSOMA MANSONI -INFECTED MICE
}

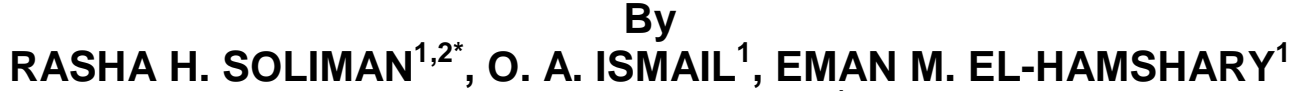 \\ AND A. H. HOSSINI ${ }^{1}$
}

Department of Parasitology ${ }^{1}$, Faculty of Medicine, Suez Canal University, Ismaillia, Egypt and Department of Parasitology ${ }^{2}$, Faculty of Medicine, Taif University, Kingdom

of Saudi Arabia ( ${ }^{*}$ Correspondence: dr_rashasoliman@yahoo.com)

\section{Abstract}

Schistosoma mansoni infection continues to be one of the most serious parasitosis worldwide due to its debilitating effects, mainly hepatic fibrosis. The present study explored the antifibrotic effect of resveratrol (RSV), either alone or in combination with praziquantel, on the murine model of intestinal schistosomiasis. We performed two parallel experiments exploring the preventive and the curative effect of RSV on inflammation and fibrosis. Parasitological measurements (adult worm burden, oogram), biochemical (AST, ALT, hydroxyproline), histopathological and histobiochemical studies were performed.

The results revealed that RSV has significant curative and preventive outcome on hepatic fibrosis and this effect is augmented when coupled with praziquantel. Other parasitological and biochemical parameters were enhanced as well.

Key words: Schistosoma mansoni; fibrosis; resveratrol; hydroxyproline; immunohistochemistry

\section{Introduction}

Schistosoma mansoni (S. mansoni) is considered one of the most important parasitic infections worldwide responsible for 4.5 million disability adjusted life losses every year (King and Dangerfield-Cha, 2008). The pathognomonic feature of $S$. mansoni is the formation of hepatic granuloma with cellular components and collagen fibers encircling the parasite ova (Burke et al, 2010). The major extracellular matrix components of the developed fibrotic granuloma are: Fibronectin secreted by macrophages (Andrade and Grimaud, 1988), proteoglycans dermatan sulfate, the interstitial collagen type I and III and heparin sulfate (Chatterjee et al, 2005). This process is the fundamental a etiology of fibrotic diseases in humans at present (Burke et al, 2010).

For more than thirty years, Praziquantel (PZQ) was regarded as the ultimate antischistosomal drug, thus ranking as the most widespread chemotherapeutic agent prescribed against this infection (Chen, 2005; Caffrey, 2007). Regrettably, drug insensitivity and even resistance reports have caught the attention of researchers over the last few years arising from long term administration of it (Cioli and Pica-Mattoccia, 2003; Wang et al, 2010). The alarming reports of PZQ failure to cure schistosomiasis in some areas demanded the extensive search for replacement regimens that can solve these drawbacks (Hanallah et al, 2003).

Resveratrol (RSV) is a natural compound found in many plants, including grapes, peanuts and berries (Vidavalur et al, 2006; Szkudelska and Szkudelski, 2010). It proved to have a wide biological activity (Das and Maulik, 2006) and its health benefits are of wide spectrum ranging from anti-cancer activity (Jang et al, 1997), metabolic diseases (Baur et al, 2006; Lagouge et al, 2006), atherosclerosis (Wu and Hsieh, 2011), diabetes (Su et al, 2006), muscular dystrophy (Hori et $a l, 2011)$. RSV also has cardioprotective and neuroprotective effects (Sun et al, 2010; Tanno et al, 2010).

The anti-cancerous effects of RSV were one of the main aspects that brought attention towards its therapeutic effects (Eibl and Unger 1990). The anti-parasitic effect was later demonstrated by several researchers where it exhibited a significant effect on visceral leishmaniasis (Jha et al, 1999) and this 
was exhibited against intracellular amastigotes and In-vitro promastigote (Kedzierski et al, 2007). Leiro et al. (2004) proposed a different range of RSV therapeutic effects against Encephalitozoon cuniculi depended on dose adjustment. Plasmodium falciparum was significantly affected by RSV administration (Son et al, 2007). Trichinella spiralis adults and emerging larvae were killed by RSV administration (Ozkoc et al, 2009). The therapeutic anti-inflammatory effect of RSV in animal models was reported by several authors (Uguralp et al, 2008; Larrosa et al, 2009; Losso et al, 2010; Wood et al, 2010).

This study was designed to investigate the possible beneficial effects of Resveratrol (RSV) on either preventing or treating $S$. mansoni induced liver fibrosis in mice either alone or combined with Praziquantel (PZQ).

\section{Materials and Methods}

Seventy CD-1 male Swiss albino pathogen-free mice (Mus musculus domesticus); 4-6 weeks and weighing 18-20g were used. The animals were provided by the animal house of the Theodor Bilharz Research Institute (TBRI), Giza. The mice were maintained on a standard commercial chow ad libitum in an air-conditioned animal house at $20-22^{\circ} \mathrm{C}$. They were divided randomly into equal groups and kept in seven different cages as10mice/cage.

Schistosoma mansoni cercariae were obtained from laboratory bred infected $B i$ omphalaria alexandrina snails in SBSC at TBRI, Giza, Egypt.

Tested drugs: 1- Praziquantel (PZQ) 600 mg tablets (Praziquantel-sedico pharmaceutical Co. $6^{\text {th }}$ October City), was given orally in a total dose of $300 \mathrm{mg} / \mathrm{kg}$ on two consecutive days, as aqueous suspension in $2 \%$ Cremophor El. 2- Resveratrol (RSV) powder was purchased from Sigma-Aldrish Chemie (Steinheim, Germany). RSV was used as freshly prepared suspension in $0.5 \%$ carboxymethyl cellulose (CMC) in distilled water before intra-gastric administration and was given in a dose of $20 \mathrm{mg} / \mathrm{kg}$ once daily (El-
Agamy et al, 2011).

Study design: All mice were infected with $S$. mansoni cercariae via subcutaneous route by $50 \pm 10$ cercariae/mouse. As for RSV \& PZQ regimens, two dosing protocols were applied intragastrically using a stomach tube in the studied groups after $4 \& 6$ weeks of infection respectively onwards. Mice infected with $S$. mansoni cercariae were divided randomly into two experimental groups; the first consisted of 30 mice and the second consisted of 40 mice.

A- The first protocol: to study the potential preventive effects of RSV on S. mansoniinduced liver fibrosis in mice. After 4 weeks of infection, the first group were divided randomly into 3 subgroups each composed of 10 mice. G1: infected non treated mice. GII: infected mice and treated with RSV at the dose of $20 \mathrm{mg} / \mathrm{kg}$ orally once daily for 2 weeks. GIII: infected mice and treated with RSV and PZQ in half of its ordinary dose, as $300 \mathrm{mg} /$ day. Mice were sacrificed at the end of $8^{\text {th }}$ week post-infection (PI).

B- The second protocol: to study the curative effects of RSV on $S$. mansoni-induced liver fibrosis in mice. After 6 weeks of infection, the second group was divided randomly into 4 subgroups each one comprising of 10 mice: GIV: infected non- treated mice. GV: infected mice treated with PZQ only $600 \mathrm{mg}$ orally for 2 consecutive days. GVI: infected mice treated with RSV only (20 $\mathrm{mg} / \mathrm{kg} /$ day) once daily for 2 another weeks. GVII: infected mice treated with PZQ at a dose of $300 \mathrm{mg} / \mathrm{kg}$ once daily orally by gavages for one day then received oral RSV $(10 \mathrm{mg} / \mathrm{kg} / \mathrm{day})$ once daily for another two weeks; PZQ was administered to eradicate worms, stop egg deposition and further fibrosis development and RSV was administered to evaluate its efficacy in decreasing development of liver fibrosis (El-Agamy et $a l, 2011)$. Mice were scarified at end of $10^{\text {th }}$ week PI.

Parasitological studies: After scarification; all mice underwent porto-mesenteric perfusion for the following studies by estimation 
of worm burden (Smithers and Terry, 1965), oogram study (Pellegrino et al, 1962) and counting number of eggs in infected intestine and liver (Cheever, 1970).

Histopathological studies were done by examining liver sections stained with hematoxylin and eosin and.or Masson's Trichrome to determine reductions in mean counts and diameters of hepatic granulomas as well as their healing in the treated groups compared to infected untreated control group. Also, counting the number and measuring the size of hepatic granulomas in S. mansoni-infected mice (Jacobs et al, 1997).

Serum biochemical measurements: Serum was collected and assayed for alanine aminotransferase (ALT) and aspartate aminotransferase (AST) by using standard enzymatic assay kits (Winn-Deen et al, 1988). Hydroxyproline (HYP) (Sigma-Aldrich Chemie, Germany) was determined colorimetrically (Woessner, 1961) and modified by SigmaAldrich (www.sigmaaldrich.com).

Immunohistochemical studies: The smooth muscle actin alpha ( $\alpha$ - SMA) (Dako Corporation, Carpinteria, Calif, USA), which is a marker of activated hepatic satellite cells (HSCs), was detected on formaldehydefixed paraffin-embedded sections by immunohistochemistry (Brennan et al, 2000).

Ethical Considerations: The study was approved by the Ethics Committee of both TBRI and Suez Canal University. The animal experiment was carried out according to The National Research Council's (NRC) Guide for the Care and Use of Laboratory Animals (NRC, 1996).

Statistical analysis: Data were collected, tabulated, statistically analyzed by statistical package SPSS. Mean (X), Standard of Error (SE) and Analysis of Variance (ANOVA or F-test) were performed. $P$ value $<0.05$ was considered significant.

\section{Results}

Treatment of mice with RSV alone mildly reduced the mean total number of worm burden. However, treatment with a combination of PZQ and RSV caused a marked and significant reduction in mean total worm burden reaching $96.3 \%$ reduction (Tab. 1). The oogram pattern after RSV treatment showed a reduction of mean mature ova and increase in dead ova. Combination of PZQ and RSV augmented its effect significantly on the mean mature ova count compared to infected control group. The mean dead ova count was significantly increased. Treatment of mice with RSV alone reduced the mean hepatic and intestinal egg load. Treatment with both PZQ and RSV significantly reduced mean hepatic and intestinal egg load dramatically to $76.5 \% \& 75.5 \%$ reduction respectively (Tab. 2).

The histopathological examination of livers of $S$. mansoni-infected mice revealed that large cellular granuloma in infected untreated control animals composed of a mixture of chronic inflammatory cells rich in eosinophils. The intact cellular miracidium is seen inside the ovum. Some granulomas are fused together to form larger ones with marked fibrosis, the surrounding liver tissues showed portal lymphocytic infiltrate (Fig. 1A\&B). Meanwhile, Hepatic fibrocellular moderate sized granulomas in infected animals, treated with RSV only were observed. The granulomas were densely packed with inflammatory cells and intact cellular miracidium inside the ovum was observed (Fig. 1C). Sometimes phagocyto-sed non-viable schistosome eggs surrounded by inflammatory cells and fibrous tissues were seen (Fig. 1D). In infected mice treated with RSV and PZQ small fibrocellular granulomas with markedly reduced granulomatous reaction and a degenerated miracidium surrounded by inflammatory cells and fibrous tissues were mainly observed (Fig. 1E\&F).

The mean hepatic granuloma diameter was $410.9 \mu \mathrm{m} \pm 7.3$ for the infected control group. Oral administration of RSV to infected mice with $S$. mansoni significantly reduced granuloma diameter to $329.4 \mu \mathrm{m} \pm 30.8(19.8 \%)$ while administration of RSV in combination with PZQ significantly reduced granuloma diameter to $250.5 \mu \mathrm{m} \pm 12.4$ (39.0\%) (Fig. 2). 
As for the hepatic granuloma count, the same findings were observed (Tab. 3)

Treatment with RSV alone resulted in significant reduction in ALT content by $32.8 \%$ when compared to infected control group while treatment with PZQ and RSV produced significant reduction by $51.4 \%$. As for AST content it was reduced by $29.2 \%$ when RSV was administered alone and insignificantly reduced by $31.1 \%$ after given a combination of RSV \& PZQ, as compared to infected control group. Hydroxyproline content was reduced by $18.1 \%$ as a consequence of RSV administration alone. Administration of RSV alone reduced Hydroxyproline content by $18.1 \%$, treatment with PZQ and RSV produced a significantly higher reduction of $61.4 \%$ in HYP content as compared to infected control group (Tab. 4).

In immunohistochemical examination of livers of $S$. mansoni-infected control mice: Many spindle to oval cells with cytoplasmic brownish staining of $\alpha$-SMA within the granulomas and in-between hepatocytes outside the granulomas were seen, indicating active fibroblastic proliferation. The same findings were observed to a lesser extent in in RSV treated group, indicating fibroblastic proliferation and fibrosis. In $\mathrm{PZQ}+\mathrm{RSV}$ treated group, very few to no positive cells were within the granulomas and in-between hepatocytes outside the granulomas, indicating marked decrease in fibroblastic proliferation and fibrosis (Fig 3).

Parasitological studies: Administration of PZQ to infected mice reduced total number of worm burden by $65.7 \%$, while treatment of mice with RSV alone diminished mean number of worm burden by $46.2 \%$. Administration of PZQ and RSV caused a marked reduction in worm burden to $86.2 \%$ (Tab. 5). As regards the oogram pattern, the infected group received PZQ treatment showed a reduction of mean immature ova, a reduction in mean mature ova and increase in dead ova. RSV administration alone affected the number of dead ova significantly and reduced the mean mature ova while hardly af- fecting the immature and dead ova. Combination of PZQ and RSV tremendously optimized its effect on mean mature ova and increased dead ova as compared to infected group (hepatic \& intestinal egg loads, treatment with both PZQ \& RSV significantly reduced the mean hepatic and intestinal egg to $72.9 \%$ \& $76.7 \%$ respectively (Tab. 6).

In histopathological examination of livers of $S$. mansoni-infected mice, sections of liver were examined for granuloma numbers and diameters. Liver sections of infected untreated mice, showed granulomas and viable ova, marked peri-granulomatous lymphocytes and plasma cells inflammatory infiltrate, marked fibrosis surrounding liver and portal lymphocytic infiltrate. In PZQ- treated group showed moderate decrease in granulomas size, containing dead ova, moderate peri-granulomatous lymphocytes and plasma cells inflammatory infiltrate with marked fibrosis. Histopathological examination showed a decrease in granulomas size, with phagocytosed miracidium surrounded by inflammatory cells and fibrous tissues in RSV-only treated group. Also, small fibro cellular granuloma with markedly reduced granulomatous reaction and a degenerated miracidium in infected mice in group received RSV and PZQ.

Hepatic granuloma in each group was examined and the mean of granuloma diameter was $502.7 \mu \mathrm{m} \pm 105.1$ in infected control. Administration of PZQ to infected mice significantly reduced granuloma diameter to $370.0 \mu \mathrm{m} \pm 22.1$ (26.4\%), RSV administration significantly reduced granuloma diameter to $333.5 \mu \mathrm{m} \pm 45.0$ (91.1\%). RSV \& PZQ Administration significantly reduced granuloma diameter to $233.1 \mu \mathrm{m} \pm 29.8$ (94.1\%) (Fig. 4). Hepatic granuloma count revealed significant reduction in RSV group and RSV plus PZQ group as compared to infected control (32.8\%, $75.2 \%$ respectively) (Tab. 7$)$.

Treatment with PZQ resulted in insignificant reduction in ALT by $4.6 \% 10$ weeks P.I, when compared to infected groups. Treatment with RSV showed $5.6 \%$ reduction. 
Administration of PZQ with RSV produced insignificant reduction in ALT by $6.4 \%$ as compared to infected control groups. Treatment with PZQ resulted in significant reduction in AST by $32.2 \%$, as compared to infected groups. Treatment with RSV resulted in significant reduction by $29.9 \%$. Treatment with PZQ and RSV produced significant reduction in AST by $70.4 \%$, as compared to infected control groups. PZQ treatment resulted in a significant reduction $(\mathrm{P}<0.001)$ in HYP by $15.2 \% 10$ weeks P.I, as compared to infected untreated group. RSV treatment showed significant reduction $(\mathrm{P}<0.001)$ by $27.9 \% 10$ weeks P.I. PZQ with RSV treatment produced significant reduction in HYP by $63.2 \% 10$ weeks P.I, as compared to infected untreated group (Tab. 8).

Immunohistochemistry: in control group,

Table 1: Worm burden and distribution in S. mansoni-infected mice treated with (RSV \pm PZQ), 8-weeks post-infection (PI)

\begin{tabular}{|c|c|c|c|c|c|}
\hline Animal group (N=10) & Female & Male & Couple & Mean total & $\%$ Reduction \\
\hline Infected control & $0.29 \pm 0.49$ & $1.71 \pm 0.49$ & $4.29 \pm 0.49$ & $10.86 \pm 1.07$ & - \\
\hline Infected treated with RSV & 0 & $1.25 \pm 1.39$ & $4.50 \pm 1.20$ & $10.25 \pm 1.58$ & $5.6 \%$ \\
\hline Infected treated with RSV+ PZQ & 0 & 0 & $0.29 \pm 0.49$ & $0.57 \pm 0.98$ & $96.3 \%$ \\
\hline p-value & 0.101 & $0.005^{* *}$ & $<0.001^{* * *}$ & $<0.001^{* * *}$ & - \\
\hline
\end{tabular}

*Significant difference from infected, control mice at $\mathrm{p}<0.05$, **Significant difference from infected, control mice at $\mathrm{p}$ $<0.01$, ***Highly significant difference from infected, control mice at $\mathrm{p}<0.001$; ANOVA test.

Table 2: Oogram pattern, hepatic \&intestinal egg load in S. mansoni-infected mice treated with (RSV \pm PZQ), 8-weeks PI.

\begin{tabular}{|c|c|c|c|c|c|c|c|}
\hline \multirow{2}{*}{$\begin{array}{l}\text { Animal group } \\
(\mathrm{N}=10)\end{array}$} & \multicolumn{3}{|c|}{ Oogram $\left(\times 10^{3}\right)$} & \multicolumn{2}{|l|}{ Hepatic egg load } & \multicolumn{2}{|l|}{ Intestinal egg load } \\
\hline & Immature & Mature & Dead & Count/gm $\left(\mathrm{x} 10^{3}\right)$ & $\%$ reduction & Count/gm $\left(\times 10^{3}\right)$ & $\%$ reduction \\
\hline Infected control & $15.9 \pm 6.3$ & $80.1 \pm 7.1$ & $4.0 \pm 0.82$ & $15.17 \pm 1.28$ & - & $15.45 \pm 1.40$ & - \\
\hline $\begin{array}{l}\text { Infected treated } \\
\text { with RSV }\end{array}$ & $18.8 \pm 6.9$ & $71.0 \pm 6.9$ & $10.3 \pm 1.2$ & $11.89 \pm 0.45$ & $21.6 \%$ & $11.89 \pm 0.58$ & $\begin{array}{l}23.0 \% \\
* * *\end{array}$ \\
\hline $\begin{array}{l}\text { Infected treated } \\
\text { with RSV+PZQ }\end{array}$ & $12.1 \pm 6.4$ & $\begin{array}{l}4.3 \pm 3.5 \\
* * *\end{array}$ & $83.6 \pm 9.4 * * *$ & $3.59 \pm 0.92$ & $76.5 \%$ & $3.78 \pm 0.60$ & $\begin{array}{c}75.5 \% \\
* * *\end{array}$ \\
\hline $\mathrm{P}$ value & 0.178 & $\begin{array}{c}<0.001 \\
\text { **** }\end{array}$ & $\begin{array}{c}<0.001 \\
* * *\end{array}$ & $\begin{array}{c}<0.001 \\
* * *\end{array}$ & & $\begin{array}{c}<0.001 \\
* * *\end{array}$ & \\
\hline
\end{tabular}

Table 3: Number of granuloma count per 5 fields in $S$. mansoni-infected mice treated with (RSV \pm PZQ), 8-weeks PI.

\begin{tabular}{|c|c|c|}
\hline Animal group $(\mathrm{n}=10)$ & No. of granulomas per 5 field & \% Reduction in granuloma mean count \\
\hline Infected control & $17.4 \pm 1.7$ & -- \\
\hline Infected treated with RSV & $12.5 \pm 0.53 * * *$ & $28.2 \%$ \\
\hline Infected treated with RSV+ PZQ & $4.7 \pm 0.95 * * *$ & $73.0 \%$ \\
\hline
\end{tabular}

Table 4: Biochemical markers in S. mansoni-infected mice treated with (RSV \pm PZQ), 8-weeks PI..

\begin{tabular}{|c|c|c|c|c|c|c|}
\hline Animal group $(\mathrm{N}=10)$ & $\begin{array}{c}\text { Serum } \\
\text { ALT(U/L) }\end{array}$ & $\begin{array}{c}\% \\
\text { reduction }\end{array}$ & $\begin{array}{c}\text { Serum } \\
\text { AST(U/L) }\end{array}$ & $\begin{array}{c}\% \\
\text { reduction }\end{array}$ & $\begin{array}{l}\text { Hydroxyproline } \\
(\mu \mathrm{g} / \mathrm{ml})\end{array}$ & $\begin{array}{c}\% \\
\text { reduction }\end{array}$ \\
\hline Infected control & $184.6 \pm 42.2$ & - & $265.1 \pm 57.5$ & - & $225.1 \pm 134.7$ & - \\
\hline Infected treated with RSV & $124 \pm 21.6^{*}$ & $32.8 \%$ & $187.8 \pm 52.1$ & $29.2 \%$ & $184.4 \pm 85.2$ & $18.1 \%$ \\
\hline
\end{tabular}

Table 5: Worm burden and distribution in S. mansoni-infected mice treated with (RSV \pm PZQ), 10 -weeks PI.

\begin{tabular}{|l|c|c|c|c|c|}
\hline \multicolumn{1}{|c|}{ Animal group (N=10) } & Female & Male & Couple & Mean total & $\%$ Reduction \\
\hline Infected control & $0.75 \pm 0.46$ & $2.25 \pm 2.25$ & $3.50 \pm 1.07$ & $10.0 \pm 1.2$ & - \\
\hline Infected treated with PZQ & 0 & $1.14 \pm 1.07$ & $1.14 \pm 1.07$ & $3.43 \pm 3.21$ & $65.7 \%$ \\
\hline Infected treated with RSV & $0.13 \pm 0.35$ & $1.25 \pm 1.17$ & $2.00 \pm 1.20$ & $5.38 \pm 2.20$ & $46.2 \%$ \\
\hline Infected treated with RSV+ PZQ & $0.38 \pm 0.52$ & $0.25 \pm 0.46$ & $0.38 \pm 0.52$ & $1.38 \pm 0.92$ & $86.2 \%$ \\
\hline p-value & $0.005 * *$ & 0.065 & $<0.001 * * *$ & $<0.001 * * *$ & - \\
\hline
\end{tabular}


Table 6: Oogram pattern, hepatic \& intestinal egg load in S. mansoni-infected mice treated with (RSV \pm PZQ), 10-weeks PI.

\begin{tabular}{|l|c|c|c|c|c|c|c|}
\hline \multirow{2}{*}{$\begin{array}{c}\text { Animal group } \\
(\mathrm{N}=10)\end{array}$} & \multicolumn{3}{|c|}{ Oogram $\left(\mathrm{x} 10^{3}\right)$} & \multicolumn{1}{c|}{ Hepatic egg load } & \multicolumn{1}{c|}{ Intestinal egg load } \\
\cline { 2 - 8 } & Immature & Mature & Dead & Count/gm $\left(\mathrm{x} 10^{3}\right)$ & $\%$ reduction & Count/gm $\left(\mathrm{x} 10^{3}\right)$ & $\%$ reduction \\
\hline Infected control & $12.6 \pm 8.5$ & $83.8 \pm 9.91$ & $3.63 \pm 2.26$ & $18.38 \pm 1.36$ & - & $20.69 \pm 1.36$ & - \\
\hline $\begin{array}{l}\text { Infected treated } \\
\text { with PZQ }\end{array}$ & $6.71 \pm 1.60$ & $1.71 \pm 1.60$ & $92.1 \pm 2.67$ & $3.80 \pm 0.19$ & $79.3 \%$ & $2.37 \pm 0.16$ & $88.5 \%$ \\
\hline $\begin{array}{l}\text { Infected treated } \\
\text { with RSV }\end{array}$ & $20.6 \pm 7.8$ & $71.9 \pm 8.83$ & $7.50 \pm 2.67$ & $16.20 \pm 1.00$ & $11.9 \%$ & $18.32 \pm 0.86$ & $11.5 \%$ \\
\hline $\begin{array}{l}\text { Infected treated } \\
\text { with RSV+PZQ }\end{array}$ & $13.1 \pm 3.72$ & $4.83 \pm 3.20$ & $81.9 \pm 7.04$ & $4.98 \pm 1.20$ & $72.9 \%$ & $4.83 \pm 0.93$ & $76.7 \%$ \\
\hline P value & $\begin{array}{c}0.002 \\
* *\end{array}$ & $\begin{array}{c}<0.001 \\
* * *\end{array}$ & $\begin{array}{c}<0.001 \\
* * *\end{array}$ & & $\begin{array}{c}<0.001 \\
* * *\end{array}$ & & $\begin{array}{c}<0.001 \\
* * *\end{array}$ \\
\hline
\end{tabular}

Table 7: Granuloma count per 5 fields in S. mansoni-infected mice treated with (RSV \pm PZQ), 10-weeks PI

\begin{tabular}{|l|c|c|}
\hline Animal group $(\mathrm{N}=10)$ & No. of granulomas per 5 field & \% Reduction in granuloma mean count \\
\hline Infected control & $14.13 \pm 2.53$ & -- \\
\hline Infected treated with PZQ & $10.43 \pm 0.53^{* * *}$ & $26.2 \%$ \\
\hline Infected treated with RSV & $9.50 \pm 1.93^{* * *}$ & $32.8 \%$ \\
\hline Infected treated with RSV+ PZQ & $3.50 \pm 1.20^{* * *}$ & $75.2 \%$ \\
\hline
\end{tabular}

Table 8: Biochemical markers $\backslash$ in $S$. mansoni-infected mice treated with $(\mathrm{RSV} \pm \mathrm{PZQ}), 10$-weeks PI.

\begin{tabular}{|l|c|c|c|c|c|c|}
\hline Animal group (N=10) & $\begin{array}{c}\text { Serum } \\
\text { ALT(U/L) }\end{array}$ & $\begin{array}{c}\% \\
\text { reduction }\end{array}$ & Serum AST(U/L) & $\begin{array}{c}\% \\
\text { reduction }\end{array}$ & $\begin{array}{c}\text { Hydroxyproline } \\
(\mu \mathrm{g} / \mathrm{ml})\end{array}$ & $\begin{array}{c}\% \\
\text { reduction }\end{array}$ \\
\hline Infected control & $211.8 \pm 94.8$ & - & $521.8 \pm 135.6$ & - & $453.2 \pm 25.2$ & - \\
\hline Infected treated with PZQ & $202.0 \pm 15.0$ & $4.6 \%$ & $353.4 \pm 19.2^{* * *}$ & $32.2 \%$ & $384.4 \pm 15.4^{* * *}$ & $15.2 \%$ \\
\hline Infected treated with RSV & $200.0 \pm 69.7$ & $5.6 \%$ & $365.8 \pm 110.1 * * *$ & $29.9 \%$ & $326.8 \pm 49.1^{* * * *}$ & $27.9 \%$ \\
\hline Infected treated with RSV+PZQ & $198.3 \pm 141.7$ & $6.4 \%$ & $154.3 \pm 63.1^{* * *}$ & $70.4 \%$ & $166.9 \pm 52.6^{* * *}$ & $63.2 \%$ \\
\hline
\end{tabular}

\section{Discussion}

Since the mouse model has a similar course to human schistosomiasis (AbdulGhani and Hassan, 2010), consequently we established the mouse schistosomiasis model through $S$. mansoni cercariae infection. Then we treated them with RSV alone or RSV plus PZQ to explore the antifibrotic potential of RSV either alone or as enhancement to the specific anti-schistosomal drug PZQ either 8 or 10 weeks post infection. The criteria required for the assessment were; worm burden, oogram changes in the hepatic and intestinal egg load, the histopathological changes in liver measured by the granuloma count and size, liver function tests reflected in ALT, AST, collagen content measured by hydroxyproline and $\alpha$-SMA determination by immunohistochemistry.

In the quest to explore the potential preventive effect of RSV on $S$. mansoni infected mice; introduction of RSV alone to infected group of mice as early as 6 weeks post infection daily for 2 weeks onward resulted in the reduction in total worm burden by $5.6 \%$ compared to their corresponding infected non treated group. This change was accompanied by the significant reduction in hepatic and intestinal egg load by $21.6 \%$ and $23.0 \%$ respectively and with a pronounced effect on the oogram pattern where the mean dead ova significantly increased and the mean mature ova significantly decreased compared to control group. The effect of RSV on adult schistosome could be attributed to its ability to inhibit tubulin polymerization (Schneider et al, 2003; Chabert et al, 2006). This presumption is also supported by the findings of Ozkoc et al. (2009) where they attributed the therapeutic effect of RSV administration on adult Trichinella spiralis to its direct effect on the parasite causing it to straighten out and lose its curling. The present study showed that coupling RSV \& PZQ resulted in a more significant reduction in total worm burden, ova count and mature ova percentages.

As a result of the effect of RSV on hepatic egg load, a significant reduction in granuloma size and count was observed $(19.8 \%$ and $28.2 \%$ respectively). The mechanism for this reduction of granuloma diameter could be explained by modulation of granulomatous hypersensitivity as a result of significant diminution in cell mediated response to soluble egg antigens which resulted from the 
effect of RSV on egg count. Subsequently, a significant improvement in liver function tests was observed in the RSV group, reflecting in the reduction of both ALT and AST levels compared to their corresponding infected non-treated control group $(32.8 \%$ and $29.2 \%$ respectively).

In the present study, hydroxyproline was chosen as a measure for estimation of collagen content because it is a sensitive marker that increases significantly during liver fibrosis reflecting the de novo synthesis of liver collagen (Ala-Kokko et al, 1987). It was observed that RSV treatment for mice had reduced hydroxyproline content by $18.1 \%$ and this effect was more pronounced when RSV was coupled with PZQ in half of its regular therapeutic dose, where it drastically reduced hydroxyproline content by $61.4 \%$ compared to the corresponding infected control group. This observation is of significant importance as a marker for the preventive effect of RSV on hepatic fibrosis as it is well established that at least five fold increases in hydroxyproline content is detected after S. mansoni infection and as a consequence, liver fibrosis increases dramatically (Kaviratne et al, 2004).

The present results coincided with the results of El-Agamy et al. (2011) who investigated the effect of oral administration of RSV in dose of $20 \mathrm{mg} / \mathrm{kg}$ once daily for 2 weeks on mice infected with $S$. mansoni for a four week period. In their study, RSV significantly reduced hydroxyproline content by $25.2 \%$ compared to their corresponding infected control group.

Moreover, the same observation was concluded by Shin and Moon (2010) who evaluated the efficacy of grape skin and seeds (which are a rich source of RSV), on hepatic injury induced by the dimethylnitrosamine $(\mathrm{DMN})$ in rats. Grape skin and seeds hindered the increase in hepatic hydroxyproline content and decreased collagen deposition, implying that grape skin and seeds may be useful in preventing the development of hepatic fibrosis. Some authors stated that the hepatoprotective activity of RSV against fibrogenesis has been explained by the capacity of this polyphenol to inhibit the activation of hepatic stellate cell through disrupting signal transduction pathway and cell cycle protein expression (Kawada et al, 1998), Manna et al. (2000) explained that RSV treatment leads to the suppression of NF-k $\beta$ activation that ultimately leads to prevention of active expression of inflammatory mediator genes. Moreover, RSV was reported to have the ability to improve the antioxidant enzymes' activity of the damaged liver (Kasdallah-Grissa et al, 2007) and decreasing oxygen free radicals (Li et al, 2007). The same findings were in the present immunohistochemistry study where the RSV group showed mild fibroblastic proliferation and fibrosis compared to the infected non-treated group. An astonishing effect indicating a marked decrease in fibroblastic proliferation and fibrosis was observed in the RSV plus PZQ treated group.

In the curative experiment which aimed to explore the ability of RSV to resolve established fibrosis, treatment of the $S$. mansoni infected mice with RSV alone resulted in the significant reduction of couple adult worms by $42.9 \%$ compared to their corresponding infected non treated group. This reduction was significantly pronounced on the female worms than males $(82.7 \%$ and $44.4 \%$ respectively).

This effect on adult worms was accompanied by a similar effect on hepatic and intestinal egg load which were significantly reduced by $11.9 \%, 11.5 \%$ respectively, with high increase in mean immature and dead ova compared to their corresponding infected non-treated group. These changes in oogram pattern and reduction in total ova count may be explained by the above mentioned pronounced effect of RSV mainly on female worms affecting its fecundity plus the reduction in total female worm burden elaborated.

Consequently RSV caused significant reduction in granuloma size $(91.1 \%)$ and count 
$(32.8 \%)$ and this was reflected in the improvement of liver function tests in the form of reduction of both ALT and AST levels by $5.6 \%$ and $29.9 \%$ respectively. Moreover, the curative effect of RSV was also demonstrated as regards hepatic fibrosis measured by the hepatic content of hydroxyproline; RSV treatment alone for 2 weeks had significantly reduced hydroxyproline content by $27.9 \%$ compared to both infected nontreated control and PZQ only treated group. This effect was significantly more enhanced when RSV treatment was introduced after stopping further egg deposition in the liver by a single dose of PZQ to explore the reversible effect of RSV on the established fibrosis. A remarkable and significant reduction in hepatic hydroxyproline content of $63.2 \%$ was observed, this reduction was significant compared to the three other groups; the control non- treated, RSV only treated and the PZQ only treated groups.

The immunohistochemistry examination proved the hydroxyproline findings, where marked difference was observed between the $\alpha$-SMA stained liver biopsy of different groups; the RSV group showed mild fibroblastic proliferation and fibrosis compared to infected non-treated group and PZQ treated group. An astonishing effect was observed in the RSV plus PZQ treated group where very few positive cells within the granulomas and in between hepatocytes indicated marked decrease in fibroblastic proliferation and fibrosis.

Hong et al. (2010) concluded that the anti fibrogenic effect of RSV was a result of reduction of mRNA expression of genes which are responsible for fibrosis (alphasmooth muscle actin, transforming growth factor beta 1, collagen type I) and consequently the reduction of hydroxyproline content. Another research on the anti fibrogenic effect of RSV on the carbon tetrachloride (CCl4) model of cirrhosis revealed astonishing results and claimed that the mechanism RSV probably acts upon is by reducing TGF-beta content and decreasing NF-kappa
B activation (Chavez et al, 2008).

While Li et al. (2010) reported that RSV activates the NAD-dependent protein deacetylase SIRT1 and inhibited TGF-beta1-induced upregulation of collagen IV and fibronectin mRNA levels, Sutra et al. (2008) reported that cardiac fibrosis, Collagen I and osteopontin expressions were prevented by RSV administration. Moreover, vasculopathy was improved in RSV-treated diabetes mellitus (DM) rats, The vascular wall thickening, collagen deposition/cross-linking, and vascular permeability were all alleviated compared with that of the untreated DM rats (Jing et al, 2010).

The RSV anti-inflammatory and antioxidant properties could be attributed to the ability to inhibit prostaglandin production, cyclooxygenase- 2 activity and nuclear factor- $\kappa \mathrm{B}(\mathrm{NF}-\kappa \mathrm{B})$ activity (Shankar et al, 2007). This antifibrinogenic effect is not organ -specific but rather involves several body organs in animal models (Zou et al, 2000; Kolgazi et al, 2006; Chavez et al, 2008; Lee et al, 2010)

The organic damage caused by schistosomiasis depended on a $\mathrm{T}$ cell response, which is critical to the granuloma formation and morbidity outcome (Burke et al, 2009). However, the failure to establish a Th2 response was correlated with early mortality while excess in Th2 led to high fibrotic response and morbidity (Hoffmann et al, 2000; Pearce and Macdonald, 2002). Thus, the key to prevent morbidity in schistosomiasis may arise by interfering with the fibrotic response itself, without compromising $\mathrm{T}$ cell response. RSV proved a candidate drug to prevent morbidity since its effect as a preventive and curative agent against schistosomal fibrosis.

\section{Conclusion}

The outcome results proved that RSV treated group showed a significant decrease in histopathological parameters, hydroxyproline, liver markers and $\alpha$-SMA. Although praziquantel is still the drug of choice for the treatment of schistosomiasis due to its high 
efficacy and higher rate of compliance with the recommended dose. It was suggested to keep searching for new alternative drugs to avoid emergence of antihelminthic drug resistance.

RSV has anti-fibrotic properties as it resulted in reduction of hepatic fibrosis. Use of RSV in combination with PZQ may provide a new approach to decrease and control hepatic fibrotic process in $S$. mansoni infection. Further studies on RSV and assessment for its toxic hazards, bioavailability in man is ongoing.

\section{References}

Abdul-Ghani, RA, Hassan, AA, 2010: Murine schistosomiasis as a model for human schistosomiasis mansoni: similarities and discrepancies. Parasitol. 107, 1:1-8.

Ala-Kokkom, L, Stenbäckm F, Ryhänen, L, 1987: Preventive effect of malotilate on carbon tetrachloride-induced liver damage and collagen accumulation in the rat. Biochem. J. 246. 2:5039.

Andrade, ZA, Grimaud, JA, 1988: Morphology of chronic collagen resorption: A study on the late stages of schistosomal granuloma involution. Am. J. Pathol. 132:389-99.

Baur, JA, Pearson, KJ, Price, NL, Jamieson, HA, Lerin, C, et al, 2006: Resveratrol improves health and survival of mice on a high-calorie diet. Nature 444, 7117:337-42.

Brennan, PA, Umar, T, Zaki, GA, Langdon, JD, Spedding, A, et al, 2000: Are myoepithelial cells responsible for the widespread expression of inducible nitric oxide synthase in pleomorphic adenoma? An immunohistochemical study. J. Oral Pathol. Med. 29, 6:279-83.

Burke, ML, Jones, MK, Gobert, GN, LI, YS, Ellis, MK, et al, 2009: Immunopathogenesis of human schistosomiasis. Parasite Immunol. 31: 163-76.

Burke, ML, McManus, DP, Ramm, GA, Duke, M, Li, Y, Jones, et al, 2010: Temporal expression of chemokines dictates the hepatic inflammatory infiltrate in a murine model of schistosomiasis. PLOS Negl. Trop. Dis. 4: e598.

Caffrey, CR, 2007: Chemotherapy of schistosomiasis, present and future. Curr. Opin. Chem. Biol. 11, 4:433-9.

Chabert, P, Fougerousse, A, Brouillard, R, 2006: Anti-mitotic properties of resveratrol ana- $\log (\mathrm{Z})-3,5,4$ '-trimethoxystilbene. Biofactors 27 , 1/4:37-46.

Chatterjee, S, Vrolix, G, Depoortere, I, Peters, T, vanMarck, E, 2005: The therapeutic effect of the neuropeptide hormone somatostatin on Schistosoma mansoni caused liver fibrosis. BMC Infect. Dis. 5:45.

Chávez, E, Reyes-Gordillo, K, Segovia, J, Shibayama, M, Tsutsumi, V, et al, 2008: Resveratrol prevents fibrosis, NF- $\mathrm{KB}$ activation and TGF- $\beta$ increases induced by chronic CCL4 treatment in rats. J. Appl. Toxicol. 28(1):35-43.

Cheever, AW, 1970: Relative resistance of the eggs of human schistosomes to digestion in potassium hydroxide. Bull. WHO 43, 4:601-3.

Chen, MG, 2005: Use of praziquantel for clinical treatment and morbidity control of schistosomiasis japonica in China: a review of 30 years' experience. Acta Trop. 96:168-76.

Cioli, D, Pica-Mattoccia, L, 2003: Praziquantel. Parasitol. Res. 90:S3-9.

Das, DK, Maulik, N, 2006: Resveratrol in cardioprotection: a therapeutic promise of alternative medicine. Mol. Interv. 6:36-47.

Eibl, H, Unger, C, 1990: Hexadecylphosphocholine: a new and selective antitumor drug. Canc.Treat. Rev. 17:233-42.

El-Agamy, DS, Shebl, AM, Said, SA, 2011: Prevention and treatment of Schistosoma mansoni- induced liver fibrosis in mice. Inflammopharmacol. 19, 6:307-16.

Hanallah, S, EL-Lakkany, N, Mahmoud, S, Mousa, M, Botros, S, 2003: Altered immunoglobulin isotype profile and anti-immature worm surface immunoglobulins in mice harboring a praziquantel resistant Schistosoma mansoni isolate. APMIS 111:1125-32.

Hoffmann, KF, Cheever, AW, Wynn, TA, 2000: IL-10 and the dangers of immune polarization: excessive type 1 and type 2 cytokine responses induce distinct forms of lethal immunopathology in murine schistosomiasis. J. Immunol, 164: 6406-16.

Hong, SW, Jung, KH, Zheng, HM, Lee, HS, Suh, JK, et al, 2010: The protective effect of resveratrol on dimethylnitrosamine-induced liver fibrosis in rats. Arch. Pharm. Res. 33, 4:601-9.

Hori, YS, Kuno, A, Hosoda, R, Tanno, M, Miura, T, et al, 2011: Resveratrol ameliorates muscular pathology in the dystrophic mdx mouse, a model for Duchenne muscular dystrophy. J. Pharmacol. Exp. Ther. 338:784-94. 
Jacobs, W, Bogers, J, Deelder, A, Wéry, M, Van Marck, E, 1997: Adult Schistosoma mansoni worms positively modulate soluble egg antigen-induced inflammatory hepatic granuloma formation in vivo: Stereological analysis and immunophenotyping of extracellular matrix proteins, adhesion molecules, and chemokines. Am. J. Pathol. 150, 6:2033-45.

Jang, M, Cai, L, Udeani, GO, Slowing, KV, Thomas, CF, et al, 1997: Cancer chemopreventive activity of resveratrol, a natural product derived from grapes. Science, 275: 218-220.

Jha, TK, Sundar, S, Thakur, CP, Bachmann, P, Karbwang, J, et al, 1999: Miltefosine, an oral agent, for the treatment of Indian visceral leishmaniasis. N. Engl. J. Med. 341:1795-800.

Jing, YH, Chen, KH, Yang, SH, Kuo, PC, Chen, JK, 2010: Resveratrol ameliorates vasculopathy in STZ-induced diabetic rats: role of AGE-RAGE signaling. Diabetes Metab. Res. Rev. 26, 3:212-22.

Kasdallah-Grissa, A, Mornagui, B, Aouani, E, Hammami, M, El May, M, et al, 2007: Resveratrol, a red wine polyphenol, attenuates ethanol-induced oxidative stress in rat liver. Life Sci. 80, 11:1033-9.

Kaviratne, M, Hesse, M, Leusink, M, Cheever, AW, Davies, SJ, et al, 2004: IL-13 activates a mechanism of tissue fibrosis that is completely TGF-beta independent. J. Immunol. 173, 6: 4020-9.

Kawada, N, Seki, S, Inoue, M, Kuroki, T, 1998: Effect of antioxidants, resveratrol, quercetin, and $\mathrm{N}$-acetylcysteine, on the functions of cultured rat hepatic stellate cells and Kupffer cells. Hepatology 27:1265-74.

Kedzierski, L, Curtis, JM, Kaminska, M, Jodynis-Liebert, J, Murias, M, 2007: In vitro antileishmanial activity of resveratrol and its hydroxylated analogues against Leishmania major promastigotes and amastigotes. Parasitol. Res. 102:91-7.

King, CH, Dangerfield-Cha, M, 2008: The unacknowledged impact of chronic schistosomiasis. Chronic Illness 4:65-79.

Kolgazi, M, Sener, G, Cetinel, S, Gedik, N, Alican, I, 2006: Resveratrol reduces renal and lung injury caused by sepsis in rats. J. Surg. Res. 134, 2:315-21.

Lagouge, M, Argmannm, C, Gerhart-Hines, Z, Meziane, H, Lerin, C, et al, 2006: Resveratrol improves mitochondrial function and pro- tects against metabolic disease by activating SIRT1 and PGC-1alpha. Cell 127:1109-22.

Larrosa, M, Yañéz-Gascón, MJ, Selma, MV, González-Sarrías, A, Toti, S, et al, 2009: Effect of a low dose of dietary resveratrol on colon microbiota, inflammation and tissue damage in a DSS-induced colitis rat model. J. Agric. Food Chem. 57, 6:2211-20.

Lee, ES, Shin, MO, Yoon, S, Moon, JO, 2010: Resveratrol inhibits dimethylnitrosamine-induced hepatic fibrosis in rats. Arch. Pharm. Res. 33, 6:925-32.

Leiro, J, Cano, E, Ubeira, FM, Orallo, F, Sanmartín, ML, 2004: In vitro effects of resveratrol on the viability and infectivity of the microsporidian Encephalitozoon cuniculi. Antimicrob. Agents Chemother. 48:2497-2501.

Li, X, Meng, Y, Wu, P, Zhang, Z, Yang, X, 2007: Angiotensin II and Aldosterone stimulating NF-rB and AP-1 activation in hepatic fibrosis of rat. Regul. Pept. 138:15-25.

Li, J, Qu, X, Ricardo, SD, Bertram, JF, Nikolic-Paterson, DJ, 2010: Resveratrol inhibits renal fibrosis in the obstructed kidney: potential role in deacetylation of Smad3. Am. J. Pathol. 177, 3:1065-71.

Losso, JN, Truax, RE, Richard, G, 2010: trans-Resveratrol inhibits hyperglycemia-induced inflammation and connexin downregulation in retinal pigment epithelial cells. J. Agric. Food Chem. 58:8246-52.

Manna, SK, Mukhopadhyay, A, Aggarwal, B B, 2000: Resveratrol suppresses TNF-induced activation of nuclear transcription factors NFKappaB, activator protein-1 and apoptosis: potential role of reactive oxygen intermediates and lipid peroxidation. J. Immunol. 164:6509-19.

NRC, 1996: (National Research Council) Guide for the Care and Use of Laboratory Animals. Washington, DC: National Academy Press.

Ozkoc, S, Tuncay, S, Delibas, SB, Ciler, A, 2009: In vitro effects of resveratrol on Trichinella spiralis. Parasitol. Res. 105:1139-43.

Pearce, EJ, MacDonald, AS, 2002: The immunobiology of schistosomiasis. Nat. Rev. Immunol. 2:499-511

Pellegrino, J, Oliveira, CA, Faria, J, Cunha, AS, 1962: New approach to screening of drugs in experimental schistosomiasis mansoni in mice. Am. J. Trop. Med. Hyg. 11:201-15.

Schneider, Y, Chabert, P, Stutzmann, J, Coelho, D, Fougerousse, A, et al, 2003: Resveratrol 
analog (Z)-3,5,4'-trimethoxystilbene is a potent anti-mitotic drug inhibiting tubulin polymerization. Int. J. Cancer 107, 2:189-96.

Shankar, S, Gyanendra, G, Srivastava, R, 2007: Chemoprevention by resveratrol: molecular mechanisms and therapeutic potential. Frontiers Biosci. 12: 4839-54.

Shin, MO, Moon, JO, 2010: Effect of dietary supplementation of grape skin and seeds on liver fibrosis induced by dimethylnitrosamine in rats. Nutr. Res. Pract. 4, 5:369-74

Smithers, SR, Terry, RJ, 1965: The infection of laboratory hosts with cercariae of Schistosoma mansoni and the recovery of the adult worms. Parasitology 55, 4:695-700.

Son, I.H, Chung, IM, Lee, SJ, Moon, HI, 2007: Antiplasmodial activity of novel stilbene derivatives isolated from Parthenocissus tricuspidata from South Korea. Parasitol. Res. 101: 237-41

Su, HC, Hung, LM, Chen, JK, 2006: Resveratrol, a red wine antioxidant, possesses an insulinlike effect in streptozotocin-induced diabetic rats. Am. J. Physiol. Endocrinol. Metab. 290: E1339-46.

Sun, AY, Wang, Q, Simonyi, A, Sun, GY, 2010: Resveratrol as a therapeutic agent for neuro-degenerative diseases. Mol. Neurobiol. 41:375-383.

Sutra, T, Oiry, C, Azay-Milhau, J, Youl, E, Magous, R, et al, 2008: Preventive effects of nutritional doses of polyphenolic molecules on cardiac fibrosis associated with metabolic syndrome: Involvement of osteopontin and oxidative stress. J. Agric. Food Chem. 56, 24:116837.

Szkudelska, K, Szkudelski, T, 2010: Resveratrol, obesity and diabetes. Eur. J. Pharmacol, 635, 1/3:1-8.

Tanno, M, Kuno, A, Yano, T, Miura, T, His- ahara, S, et al, 2010: Induction of manganese superoxide dismutase by nuclear translocation and activation of SIRT1 promotes cell survival in chronic heart failure J. Biol. Chem. 285:837582.

Uguralp, S, Irsi, C, Aksoy, T, Karabulut, AB, Kirimlioglu, H, et al, 2008: Resveratrol attenuates inflammation and stricture formation in experimental caustic esophageal burns. Pediatr. Surg. Int. 24, 4:425-30.

Vidavalur, R, Otani, H, Singal, PK, Maulik, N, 2006: Significance of wine and resveratrol in cardiovascular diseases: French paradox revisited. Exp. Clin. Cardiol. 11:217-25.

Wang, W, Dai, JR, Li, HJ, Shen, XH, Liang, YS, 2010: Is there reduced susceptibility to praziquantel in Schistosoma japonicum? Evidence from China. Parasitology 137, 13:1905-12.

Winn-Deen, ES, David, H, Sigler, G, Chavez, R, 1988: Development of a direct assay for alpha-amylase. Clin. Chem. 34, 10:2005-8.

Woessnerm, JF, 1961: The determination of hydroxyproline in tissue and protein samples containing small proportions of this amino acid. Arch. Biochem. Biophys. 93:440-7.

Wood, LG, Wark, PAB, Garg, ML, 2010: Antioxidant and anti-inflammatory effects of resveratrol in airway disease. Antioxid Redox Signal 13:1535-48.

Wum, JM, Hsieh, TC, 2011: Resveratrol: A cardioprotective substance. Ann. New York Acad. Sci. 1215:16-21.

www.sigmaaldrich.com/catalog/product/sigma/ mak008?lang=en\&region=EG.

Zou, J, Huang, Y, Cao, K, Yang, G, Yin, H, Len, J, et al, 2000: Effect of resveratrol on intimal hyperplasia after endothelial denudation in an experimental rabbit model. Life Sci. 68, 2: 153-63.

\section{Explanation of figures}

Fig. 1: Sections through liver of mice of infected control (A\&B), RSV treated (C\&D) and PZQ plus RSV treated (E\&F) 8 weeks PI. H\&E; (A, C, E), Masson's Trichrome (B, D, F) X200.

Fig. 2: Percent reduction in hepatic granuloma diameter in $S$. mansoni-infected mice in different animal groups (preventive study), 8-weeks PI.

Fig. 3: Sections of liver tissues of study groups stained for smooth muscle actin alpha ( $\alpha$ - SMA). (A\&B) for infected control group; (C\&D) for RSV treated group and (E\&F) PZQ plus RSV treated group, 8 weeks post- infection. Arrows point the cytoplasmic brownish staining of $\alpha$-SMA (A, C, F: X400, B, D, E: X100).

Fig. 4: Percent reduction in granuloma diameter in S. mansoni-infected mice in different animal groups (curative study), 10weeks PI.

Fig. 5: Sections of liver tissues of study groups stained for smooth muscle actin alpha ( $\alpha$ - SMA). (A\&B) for infected control group; $(C \& D)$ for infected mice and treated with PZQ, $(E \& F)$ for RSV treated group and $(G \& H)$ for PZQ plus RSV treated group, 10 weeks post- infection. Arrows point the cytoplasmic brownish staining of $\alpha$-SMA (A, B, C, D, E, G: X400, F, H: $\mathrm{X} 100$ ). 


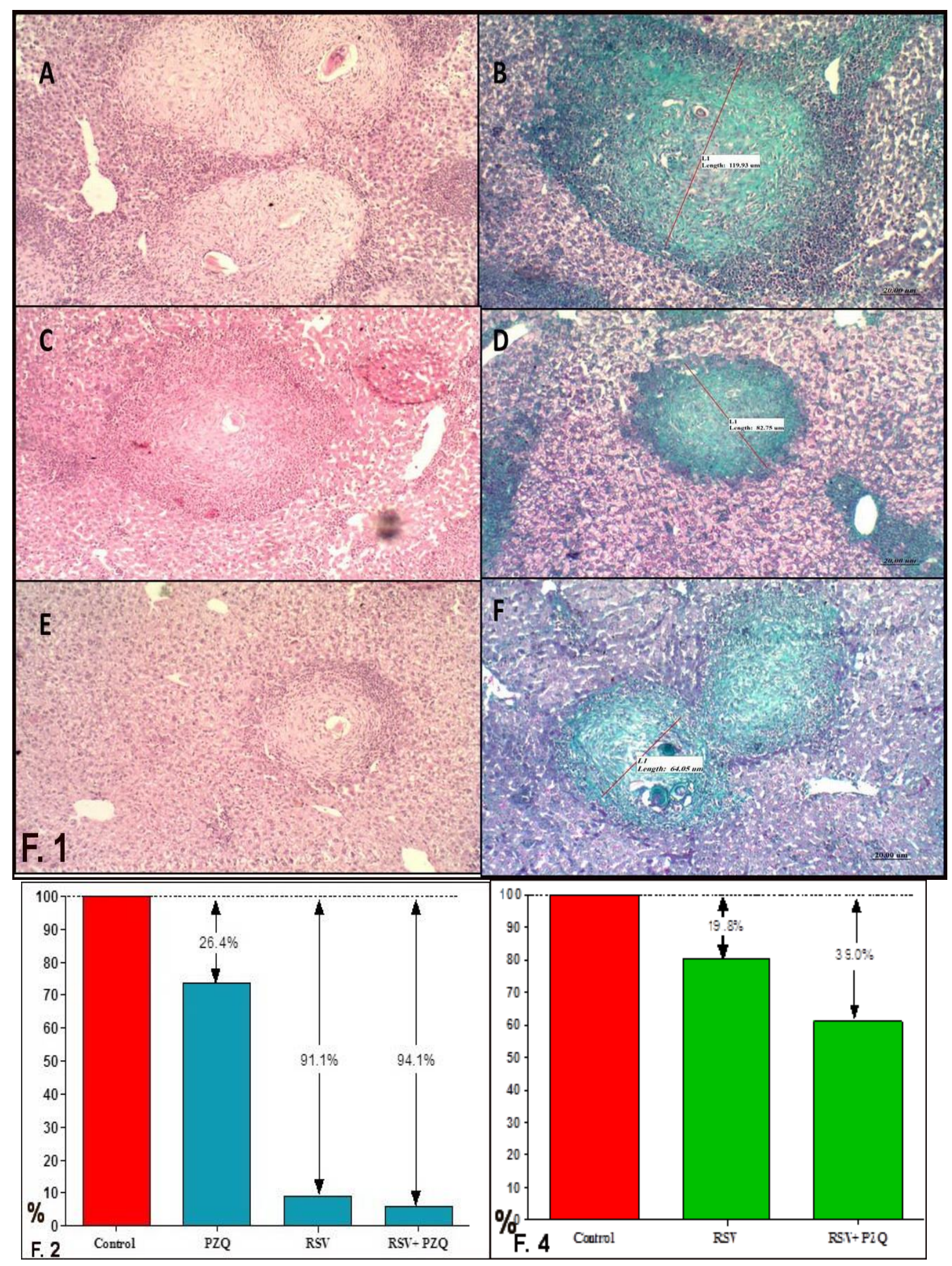




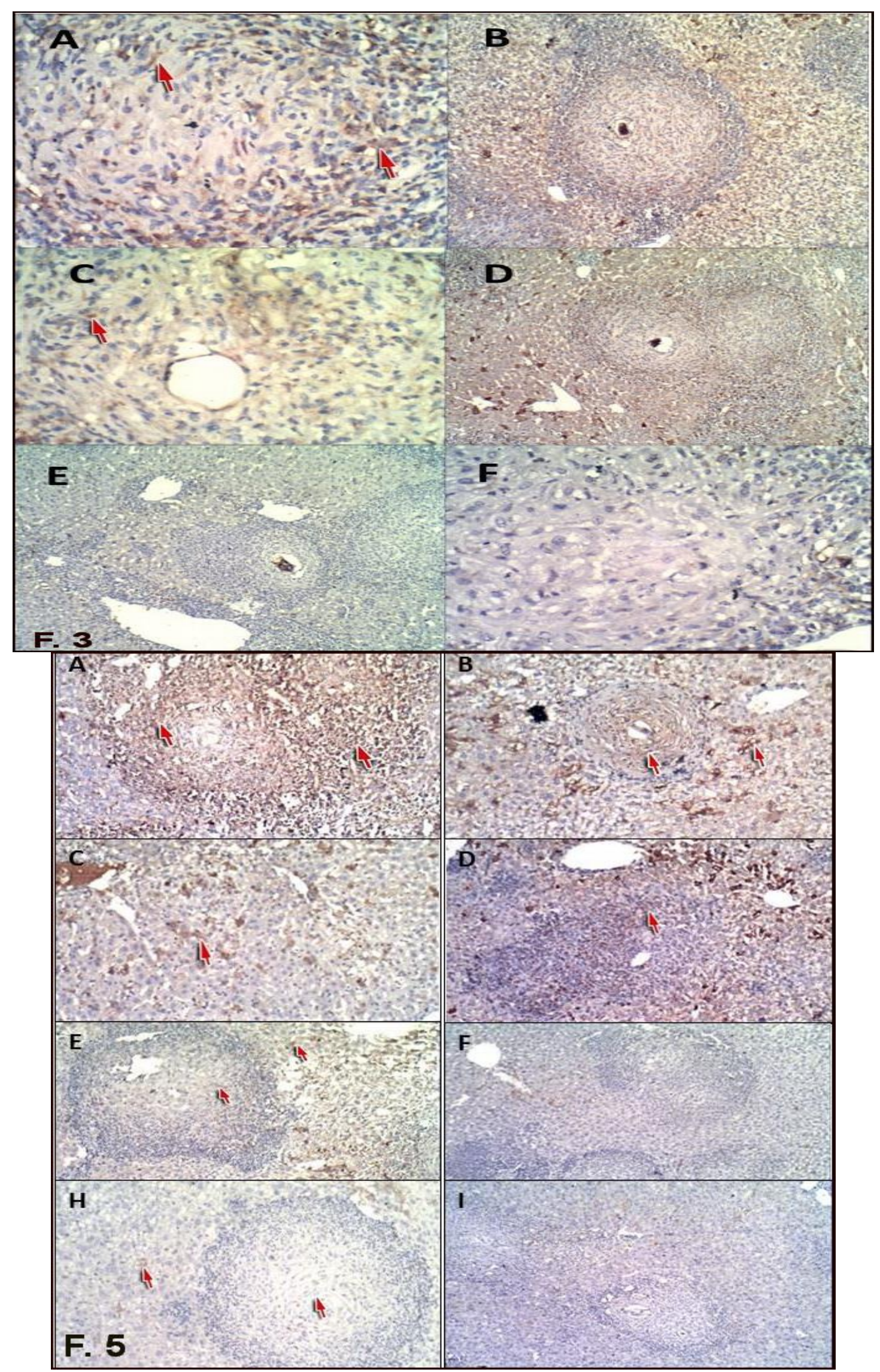

